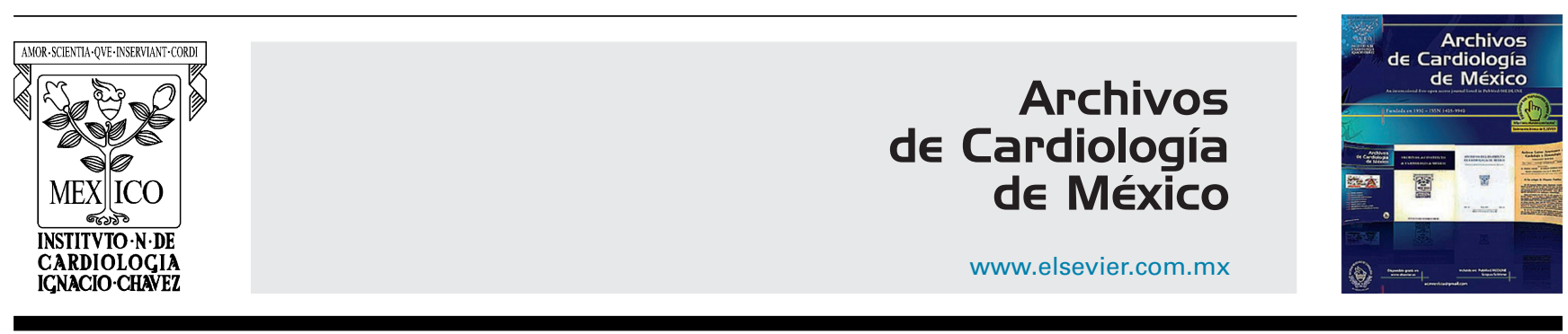

CARTAS CIENTÍFICAS

\section{Trombos biventriculares, embolismo pulmonar y miocardiopatía dilatada en una paciente con síndrome antifosfolípido}

\section{Biventricular thrombi, pulmonary embolism and dilated cardiomyopathy in a patient with antiphospholipid syndrome}

\section{Introducción}

El síndrome antifosfolípido (SAF) es una enfermedad sistémica autoinmune, caracterizada por la detección plasmática de anticuerpos antifosfolípidos y manifestaciones clínicas como trombosis venosa o trombosis arterial recurrente, trombocitopenia, abortos recurrentes y anemia hemolítica autoinmune, además de alteraciones cardiacas, neurológicas y dermatológicas. Constituye la principal causa adquirida de hipercoagulabilidad, estando presente en el $2 \%$ de la población general y conlleva una alta morbimortalidad ${ }^{1}$.

A nivel cardiaco, este síndrome puede causar afectación valvular (endocarditis seudoinfecciosa, valvulopatías con engrosamiento valvular, etc.), puede comportarse como factor de riesgo independiente para cardiopatía isquémica (síndrome coronario agudo, trombosis de la microcirculación, oclusión de bypass coronarios, trombos intracardiacos y miocardiopatías), e hipertensión pulmonar ${ }^{2}$. Los hallazgos ecocardiográficos más comunes en pacientes con SAF son vegetaciones valvulares o engrosamiento de las valvas de la válvula afectada. Estos hallazgos son más frecuentes que los trombos intracardiacos ${ }^{3}$.

\section{Caso clínico}

Paciente mujer de 45 años con antecedente de hipertensión arterial de larga duración, tratada irregularmente, acude a nuestro hospital por presentar tos seca de 3 semanas de duración, acompañada de aumento de temperatura corporal no cuantificada, recibió antibioticoterapia empírica, sin mejoría. Una semana antes de su ingreso presenta disnea progresiva, que progresa a ortopnea. Paciente obesa quien al examen físico presenta ruidos cardiacos hipofonéticos y crepitantes basales bilaterales. El electrocardiograma mostró crecimiento auricular derecho y trastornos inespecíficos de la repolarización ventricular. Inicialmente, la paciente recibió antibióticos de amplio espectro, sin mejoría de los síntomas respiratorios, ni disminución de los agregados pulmonares. La paciente fue evaluada por el servicio de cardiología y se realizó ecocardiograma transtorácico en el cual se observó ventrículo izquierdo (VI) dilatado con hipocinesia global, FEVI 30\%, ventrículo derecho (VD) dilatado, TAPSE $13 \mathrm{~mm}$, insuficiencia mitral, tricuspídea y pulmonar leve. La presión sistólica de la arteria pulmonar fue estimada en $45 \mathrm{mmHg}$. Se observaron imágenes ecogénicas móviles en el $\mathrm{VI}$, sugestivas de trombo unidas al ápex, septum interventricular y al tracto de salida del VI de $42 \times 34 \mathrm{~mm}$, y en el VD se observó trombo en tránsito, unido a la pared anterior y septum interventricular de $25 \times 27 \mathrm{~mm}$ (fig. 1). Se realizó eco-Doppler de miembros inferiores y se encontró trombosis venosa profunda en vena femoral derecha y vena poplítea derecha. Tres días después de haberse efectuado el ecocardiograma, se realizó angiotomografía de tórax (fig. 2) y se observó dilatación del tronco y de las ramas de la arteria pulmonar con embolismo pulmonar agudo submasivo en ambas ramas, con múltiples imágenes hipodensas centrales, con bordes irregulares que ocupaban más del $75 \%$ de la luz que se distribuye en las ramas subsegmentarias de forma dispersa. Además se observó dilatación severa de las cámaras cardiacas con presencia de imágenes sugestivas de trombos localizados en el septum del VI con extensión inferior y anterior $(67 \times 15 \mathrm{~mm}$ y $65 \times 38 \mathrm{~mm})$, no se observaron trombos en el VD. Después de estos hallazgos, se encontraron títulos positivos de anticuerpos anticardiolipina lgG, diagnosticándose síndrome antifosfolípido. Las pruebas para anticuerpos antinucleares y anticuerpos anti-DNA fueron negativas, descartándose lupus.

\section{Discusión}

El síndrome antifosfolípido ha sido asociado con eventos trombóticos venosos y arteriales ${ }^{4}$. La trombosis 


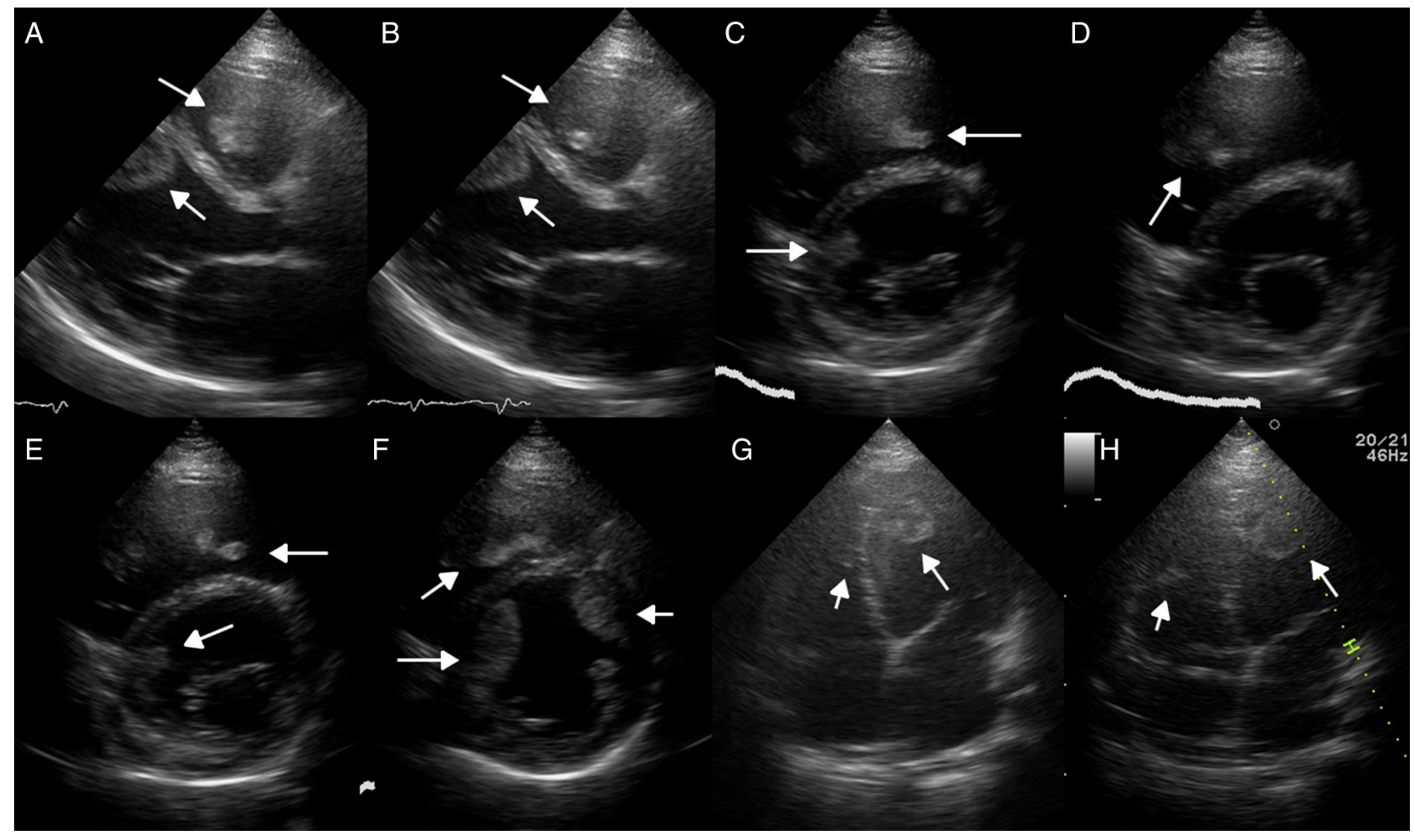

Figura 1 A, B) Vista en eje paraesternal largo donde se observan trombos en VD y VI (flechas). C-E) Vista en eje paraesternal corto a nivel basal modificado, muestra la presencia de trombos en ambos ventrículos (flechas). F) Vista en eje paraesternal corto a nivel de músculos papilares modificado, muestra trombos en VD y VI (flechas). G, H) Vista apical de 4 cámaras, muestra trombo mural adherido en ápex y septum del VI, además se observa trombo mural en VD (flechas).

intracardiaca raramente ocurre, excepto en presencia de disfunción ventricular, puede ser encontrada en cualquier cámara cardiaca siendo, sin embargo, más común del lado derecho, y constituye una causa potencial de embolismo sistémico o pulmonar ${ }^{1}$. En el presente caso, la aparición de trombos en ambos ventrículos se atribuye al SAF. Pocos casos de trombos biventriculares en presencia de síndrome antifosfolípido han sido publicados ${ }^{1,5}$.

El SAF es diagnosticado por la presencia de 2 componentes mayores: clínico (al menos una ocurrencia de trombosis vascular, trombosis venosa superficial, complicaciones del embarazo como abortos recurrentes, etc.) y hallazgos de laboratorio (presencia de al menos un tipo de anticuerpo antifosfolípido: IgG y/o lgM de anticuerpos anticardiolipina, IgG o IgM de anticuerpos anti-beta2-glicoproteína I, anticoagulante lúpico ${ }^{6}$.

Aún no está definido cuál es el mejor tratamiento para estos pacientes: administración de heparina, trombolisis, anticoagulación con warfarina o escisión del trombo ${ }^{1}$. Nuestra paciente se anticoaguló con warfarina mostrando evolución satisfactoria y fue egresada con dicho tratamiento con international normalized ratio (INR) entre 2-3. Se determinó que la probable causa de la disfunción ventricular severa en este caso es la cardiopatía hipertensiva, razón por la cual también recibió tratamiento para insuficiencia cardiaca, sin complicaciones. Los pacientes portadores de SAF tienen alto riesgo de desarrollar trombos intracardiacos, sin embargo, el trombo puede ser tratado con warfarina exitosamente. Para evitar la formación de trombos en todos los pacientes con SAF está indicada la warfarina ${ }^{3}$.

A pesar de no tener resonancia magnética cardiaca $u$ otros paraclínicos para descartar miocarditis, no se plantea en nuestro caso el diagnóstico de miocarditis inducida por embolismo pulmonar ${ }^{7}$ ya que la dilatación y disfunción de ambos ventrículos fue documentada, previa a la migración de los trombos del VD a las arterias pulmonares. 


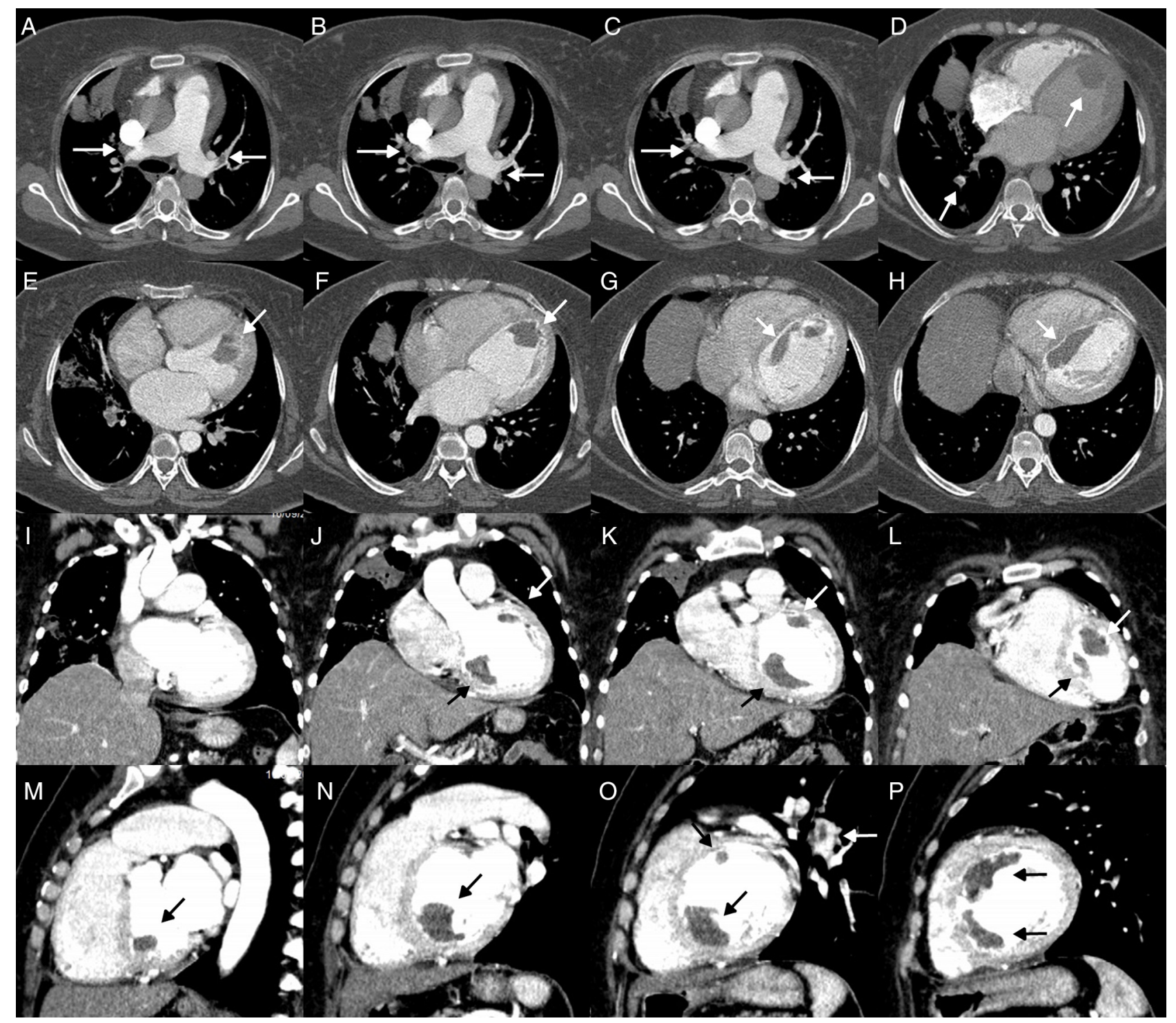

Figura 2 Angiotomografía de tórax que confirma la presencia de trombos en VD y VI. A-D) Vista axial que muestra evaluación del corazón derecho y arteria pulmonar, se observan trombos en ambas ramas de la arteria pulmonar, ramas subsegmentarias y trombo en VI (flechas). E-H) Vista axial que muestra la evaluación del corazón izquierdo, se observa trombo en $\mathrm{VI}$ adherido a septum con extensión inferior y anterior $(67 \times 15 \mathrm{~mm}$ y $65 \times 38 \mathrm{~mm})$ (flechas). I-L) Vista coronal. M-P) Vista sagital, muestra trombo ventricular izquierdo. En (0) se observa trombo en la rama izquierda de la arteria pulmonar (flechas).

\section{Financiación}

No se recibió patrocinio de ningún tipo para llevar a cabo este artículo.

\section{Bibliografía}

1. Galvão Gonçalves LF, Silveira Souto FM, Nascimento Faro F, et al. Biventricular thrombus and endomyocardial fibrosis in antiphospholipid syndrome. Arq Bras Cardiol. 2012;99:e162-5.
2. Zanazzi DD. Síndrome antifosfolipídico y afectación cardiovascular. Insuf Card. 2014;2:66-76.

3. Cianciulli TF, Saccheri MC, Lax JA, et al. Left ventricular thrombus mimicking primary cardiac tumor in a patient with primary antiphospholipid syndrome and recurrent systemic embolism. Cardiol J. 2009;16:560-3.

4. De Agustín JA, Núñez-Gil IJ, Ruiz-Mateos B, et al. Calcified right ventricular thrombus and antiphospholipid syndrome. Eur J Echocardiogr. 2009;10:471-2.

5. Hashash JG, Zeineh NS, Crock FW. Multiple intracardiac thrombi. Cleve Clin J Med. 2013;80:415-6.

6. Erkan D, Schur PH. Diagnosis of the antiphospholipid syndrome. En: UpToDate [consultado 25 Ene 2016]. Disponi- 
ble en: http://www.uptodate.com/contents/diagnosis-of-theantiphospholipid-syndrome.

7. Begieneman MVP, van de Goot FRW, van der Bilt IAC, et al. Pulmonary embolism causes endomyocarditis in the human heart. Heart. 2008;94:450-6.

\section{Carlos Eduardo Vergara-Uzcategui*}

Servicio de Cardiología, Instituto de Investigaciones Cardiovasculares, Hospital Universitario de Los Andes, Universidad de Los Andes, Mérida, Venezuela
* Avenida 16 de Septiembre, Hospital Universitario de Los Andes, Nivel Emergencia, Mérida, Venezuela, Código postal 05101.

Correo electrónico: carting1@gmail.com

http://dx.doi.org/10.1016/j.acmx.2016.06.001 $1405-9940$

(c) 2016 Instituto Nacional de Cardiología Ignacio Chávez. Publicado por Masson Doyma México S.A. Este es un artículo Open Access bajo la licencia CC BY-NC-ND (http://creativecommons.org/ licenses/by-nc-nd/4.0/).

\section{Síndrome platipnea-ortodesoxia secundario a cortocircuito intracardiaco: ¿cuestión de orientación?}

\section{Platypnea-orthodeoxia syndrome secondary to intracardiac shunt: Orientation issue?}

\section{Sr. Editor:}

El síndrome platipnea-ortodesoxia (SPO) se define como la aparición de disnea e hipoxemia en sedestación o bipedestación, con mejoría de ambas condiciones en decúbito. Descrito hace más de medio siglo, continúa siendo un reto diagnóstico para el clínico por tratarse de una enfermedad infrecuente y que requiere un alto nivel de sospecha ${ }^{1}$. Además, tras confirmar el diagnóstico, una gran proporción de pacientes puede beneficiarse de un tratamiento específico.

Presentamos el caso de una paciente de 80 años que ingresa en nuestro servicio por disnea. Entre sus antecedentes más relevantes figuran hipertensión arterial, hematoma intraparenquimatoso temporal izquierdo y lesiones isquémicas cerebelosas con marcha inestable, extrapiramidalismo y bradilalia como secuelas. Desde hace 2 años, además, presentaba parálisis diafragmática derecha secundaria a axonotmesis del nervio frénico tras fractura humeral, con oxigenoterapia domiciliaria desde entonces. Recientemente había ingresado en neumología presentando estudios de imagen y pruebas de función respiratoria dentro de la normalidad. El ecocardiograma transtorácico realizado entonces, demostró la presencia de aneurisma del septo interauricular con foramen oval permeable (FOP) y un posible cortocircuito derecha-izquierda por paso de solución agitada únicamente con maniobras de Valsalva. Se describía también dilatación moderada de la raíz aórtica $\left(26 \mathrm{~mm} / \mathrm{m}^{2}\right)$.

En el momento del ingreso actual, sin signos de insuficiencia cardiaca se encontraba normotensión y taquicardia sinusal a $110 \mathrm{lpm}$, destacando una saturación de oxígeno basal del $70 \%$, con datos de insuficiencia respiratoria parcial en la gasometría arterial. Al suplementar oxígeno con Ventimask ${ }^{\circledR} 60 \%$, la saturación arterial aumentó hasta el 88 $90 \%$. Durante el ingreso se objetivó desaturación importante en sedestación, con aumento de hasta un 10\% al adoptar posición en decúbito. El ecocardiograma transesofágico confirmó la presencia de aneurisma del septo interauricular con FOP y cortocircuito continuo derecha-izquierda mediante Doppler color (fig. 1A). Demostró también paso de solución agitada, de aurícula derecha a aurícula izquierda, infundida a través de una vía venosa periférica canalizada en el miembro inferior izquierdo (fig. 1B). Las características del cortocircuito no cambiaron con las modificaciones de postura. Por otro lado se realizó una tomografía computarizada torácica que descartó la presencia de cortocircuitos extracardiacos y en el estudio hemodinámico no se encontraron datos de hipertensión pulmonar.

Finalmente se procedió al cierre del FOP mediante el implante de un dispositivo Amplatzer ${ }^{\circledR}$ de $25 \mathrm{~mm}$, con buen resultado y sin complicaciones (fig. 2). La mejoría clí-

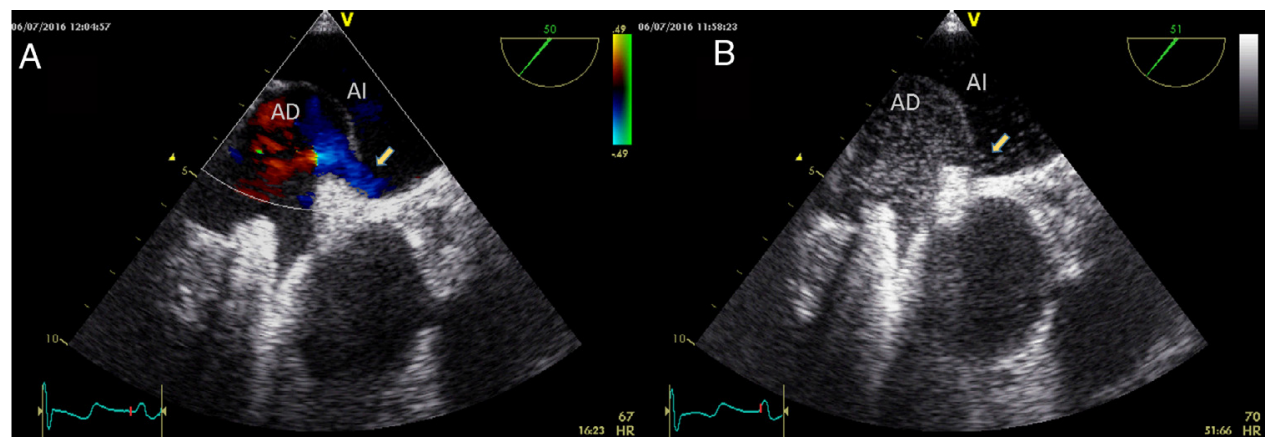

Figura 1 Ecocardiograma transesofágico. A) Doppler color que demuestra la existencia del FOP con cortocircuito derechaizquierda (flecha); B) Paso de solución agitada de aurícula derecha a aurícula izquierda (flecha), infundida a través del miembro inferior. 